\title{
OCORRÊNCIA E CARACTERIZAÇÃO MORFOLÓGICA DE FIBROIDIUM EMILIAE-SONCHIFOLIAE EM PLANTAS DE EMILIA SONCHIFOLIA EM IPAMERI, GOIÁS
}

Gustavo Henrique Silva Peixoto ${ }^{1}$, Camila Vilela Vasconcelos ${ }^{2}$, Maysa Pereira Martins Teixeira ${ }^{3}$, Thiago Alves Santos de Oliveira ${ }^{4}$, Daniel Diego Costa Carvalho

\begin{abstract}
RESUMO - O conhecimento das doenças das plantas e seus respectivos agentes causais é importante quando se pensa na adoção de medidas para o manejo integrado e no aumento da produtividade. O objetivo deste trabalho caracterizar o agente causal do oídio ocorrente em plantas de falsa serralha (Emilia sonchifolia) proveniente de áreas adjacentes aos campos experimentais de horticultura do campus universitário da Universidade Estadual de Goiás (UEG), Ipameri, Brasil. Após inspeções nas áreas mencionadas, folhas de E. sonchifolia exibindo sintomas de oídio foram levadas ao Laboratório de Fitopatologia da UEG e examinadas em estereomicroscópio para caracterização dos sintomas e posterior raspagem das estruturas do fungo para confecção de lâminas semi-permanentes. Em seguida, realizou-se o registro de imagens e a caracterização morfológica de conídios, pela medição de 30 estruturas em microscópio de luz. O comprimento médio de conídios encontrados em falsa serralha foi de $27,8 \times 12,7 \mu \mathrm{m}$, cuja média da relação comprimento/largura (C/L) foi de 2,1. Os dados obtidos foram suficientes para cofirmar o agente cuasal do oídio em sua fase anamórfica, utilizando plantas de E. sonchifolia como hospedeiro alternativo da doença. Este é o primeiro relato da ocorrência de Fibroidium emiliae-sonchifoliae em E. sonchifolia no Estado de Goiás.
\end{abstract}

Palavras chave: hospedeiro alternativo, micologia, plantas daninhas.

\section{OCCURRENCE AND MORPHOLOGICAL CHARACTERIZATION OF FIBROIDIUM EMILIAE-SONCHIFOLIAE ON LILAC TASSEL FLOWER PLANTS IN IPAMERI, GOIÁS}

\begin{abstract}
The knowledge of plant diseases and their respective causal agents is important when considering adoption of measures for integrated management and increase productivity. The objective of this work was to characterize the causal agent of the powdery mildew occurring in lilac tassel flower plants (Emilia sonchifolia) from adjacent areas of horticulture experimental fields of the Universidade Estadual de Goiás (UEG), Ipameri, Brazil. After inspections in the mentioned areas, E. sonchifolia leaves exhibiting symptoms of powdery mildew were taken to the Phytopathology Laboratory of UEG and examined in a stereomicroscope aiming to characterize the symptoms and then scraping of the fungus structure to make semi-permanent slide mountings. Then, it was performed a capture of images and the morphological characterization of the conidia, by measuring 30 structures under a light microscope. The mean length of conidia found in lilac tassel flower was $27.8 \times 12.7$ $\mu m$, whose mean of length/width ratio $(L / W)$ was 2.1. The data obtained were enough to confirm the powdery mildew causal agent in its anamorphic phase, using E. sonchifolia plants as alternative host of the disease. This Is the first report of the occurrence of Fibroidium emiliae-sonchifoliae in E. sonchifolia in Goias State.
\end{abstract}

Keywords: alternative host, weeds, mycology.

\footnotetext{
${ }^{1}$ Graduando em Agronomia, Universidade Estadual de Goiás, Rodovia GO 330, km 241, Anel Viário, Setor Universitário, 75780-000, Ipameri, GO, Brasil.gugspeixoto@gmail.com

${ }^{2}$ Mestre em Produção Vegetal, Universidade Estadual de Goiás, Ipameri, GO, Brasil. camilavilela85@yahoo.com.br

${ }^{3}$ Graduanda em Agronomia, Universidade Estadual de Goiás, Ipameri, GO, Brasil. maysapmteixeira@outlook.com

${ }^{4}$ Professor Doutor em Fitopatologia, Universidade Estadual de Feira de Santana, Avenida Transnordestina, Novo Horizonte, 44036-900, Feira de Santana, Bahia, Brasil. oliveira.tas@gmail.com

${ }^{5}$ Professor Doutor em Fitopatologia, Universidade Estadual de Goiás, Ipameri, GO, Brasil. daniel.carvalho@ueg.br
} 


\section{INTRODUÇÃO}

Emilia sonchifolia (L.) DC. ex Wight, também conhecida como falsa-serralha, é uma espécie vegetal frequente em regiões tropicais e subtropicais. É considerada como planta invasora presente em quase todo território brasileiro, a qual realiza dispersão por sementes em áreas agrícolas, terrenos baldios e áreas urbanas, possuindo amplo uso na medicina popular em casos de inflamações, cortes, feridas, convulsões, reumatismo e mordidas de insetos (Yamashita et al., 2009; Couto et al., 2011).

As doenças conhecidas como oídios ou míldios pulverulentos são causadas por fungos que recebem esta denominação devido à pulverulência do micélio e das cadeias de conídios que se desenvolvem em diversos órgãos vegetais, como meristemas, ramos jovens, flores, frutos em formação e, principalmente, na face adaxial das folhas (Bedendo et al., 2011; Gonzalez et al., 2013; Rabelo et al., 2017). O oídio dissemina-se através do vento, respingo de chuvas e também pelo contato com plantas contaminadas e, ao infectar a planta, forma haustórios no interior das células do hospedeiro para obtenção de nutrientes (Tumura et al., 2013).

Além da própria competição com a cultura, Miléo et al. (2007) evidencia como efeito deletério das plantas daninhas, a associação com microrganismos patogênicos que possam afetar a cultura principal, funcionando como um hospedeiro alternativo e um mecanismo de sobrevivência para o patógeno agente causal da doença. O oídio possui um vasto banco de hospedeiros, em diferentes plantas daninhas como Bidens pilosa (picãopreto), Emilia sonchifolia (falsa-serralha), Ageratum conyzoides (mentrasto) e Sonchus asper (serralha), todas pertencentes à família Asteraceae (Ferreira et al., 2002). Portanto, a identificação de fontes de inoculo e de sobrevivência de fitopatógenos e suas interações com os diferentes componentes biológicos de um agroecossistema é fundamental para o estabelecimento de práticas de manejo adequadas, visando ao controle de fitopatógenos (Valarini \& Spadotto, 1995).

Em decorrência do fato de que as plantas cultivadas estão cada vez mais sujeitas à incidência de novas doenças e ao aumento da agressividade das já existentes, o constante monitoramento das condições fitossanitárias das culturas faz-se necessário, permitindo que as potencialidades dos danos dessas doenças sejam mensuradas, auxiliando em novas estratégias de controle, porém poucos trabalhos têm sido publicados no Brasil sobre hospedeiros alternativos de fitopatógenos (Lima et al., 2004). O objetivo deste trabalho foi realizar a caracterização do agente causal do oídio ocorrente em plantas de falsa serralha (Emilia sonchifolia) proveniente de áreas adjacentes aos campos experimentais de olerícolas do campus universitário da Universidade Estadual de Goiás (UEG), Ipameri, Brasil.

\section{MATERIAL E MÉTODOS}

Em inspeções de campo foram realizadas avaliações fitossanitárias em plantas daninhas como hospedeiras alternativas de fitopatógenos, em que as observações foram direcionadas para a planta daninha de maior ocorrência (E. sonchifolia) em cultivos de cucurbitáceas no Setor de Horticultura da Universidade Estadual de Goiás (UEG), campus Ipameri, Goiás $\left(17^{\circ} 43^{\prime} 00^{\prime \prime} \mathrm{S}\right.$, $48^{\circ} 08^{\prime} 40^{\prime \prime} \mathrm{W}, 920 \mathrm{~m}$ ), em 08 de julho de 2013, englobando os quadros sintomatológicos da planta daninha mencionada. As plantas de falsa-serralha ocorrente no Setor de Horticultura, exibindo sintomas de oídio, foram coletadas e levadas ao Laboratório de Fitopatologia da UEG para serem examinadas em estereomicroscópio e terem sua sintomatologia caracterizada. Em seguida, lâminas para estudo das estruturas do patógeno foram confeccionadas empregando-se lactoglicerol e azul de algodão como meio de montagem, mediante remoção de micélio e estruturas fúngicas encontradas sobre os tecidos vegetais atacados pelo patógeno. Imagens de estruturas do fungo foram capturadas em microscópio de luz Leica DM500, com câmera digital ICC50. Realizouse a caracterização das estruturas dos artroconídios maduros e células do conidióforos (célula basal, célula generativa, conídio em primeiro estádio e conídio em segundo estádio) através do software LAS EZ (100x), obtendo-se 30 medidas para cada estrutura mensurada.

\section{RESULTADOS E DISCUSSÃO}

Após o levantamento de doenças, sintomas típicos de oídio foram observados na face adaxial de folhas de plantas de falsa serralha, que ocorriam como plantas daninhas no Setor de Horticultura da UEG. As folhas exibiam uma massa pulverulenta branca-acinzentada na face adaxial (Figura 1A), compreendendo micélio e conídios do fungo agente causal do oídio. Após medir as estruturas do fungo, foi verificado que o artroconídio maduro (C) teve $23,1-31,9 \times 11,3-14,5 \mu \mathrm{m}(26,8$ x $12,3 \mu \mathrm{m})$ e uma relação de Comprimento/Largura (C/ 
L) de 2,1; conídio em segundo estádio (C2) apresentou 17,0 - 27,9 x 9,5 - 15,6 ìm (22,6 x 12,9 ìm) e relação $\mathrm{C} / \mathrm{L}$ de 1,7 ; conídio em primeiro estádio (C1) teve $12,0-24,6$ x 8,2-14,6 ìm (18,5 x 11,8 ìm) e relação $\mathrm{C} / \mathrm{L}$ de 1,5 ; célula generativa (CG) $9,5-21,7 \times 7,7$ - 14,2 ìm (15,4 x 10,4 ìm) e C/L de 1,4; célula basal (CB) $45,3-91,4$ x 8,3-12,6 ìm (66,8 x 10,1 ìm) e C/ L de 6,4 (Figura 1B).

Quanto ao comprimento e largura da célula basal do conidióforo, BRAUN \& COOK (2012) encontraram para F. emiliae-sonchifoliae as dimensões de 48,0 72,0 x 12,0 - 13,0 ìm e relação Comprimento/Largura (C/L) de 4,0 - 5,5 para célula basal, corroborando com o presente trabalho onde foi mensuradas células basais apresentando 45,3-91,4 x 8,3-12,6 ìm. No entanto com relação ao artroconídio maduro, Braun \& Cook (2012) obtiveram $32,0-48,0 \times 12,0-23,0$ ìm, enquanto que para o presente trabalho foi encontrado $23,1-$ 31,9 x 11,3-14,5 ìm. Entretanto, esta diferença encontrada entre os dois trabalhos não levantam dúvidas quanto a identidade do fungo, visto que nos levantamentos realizados na bibliografia, outras espécies possuem dimensões muito diferentes. Ademais, outros trabalhos evidenciaram este acontecimento para mesma espécie
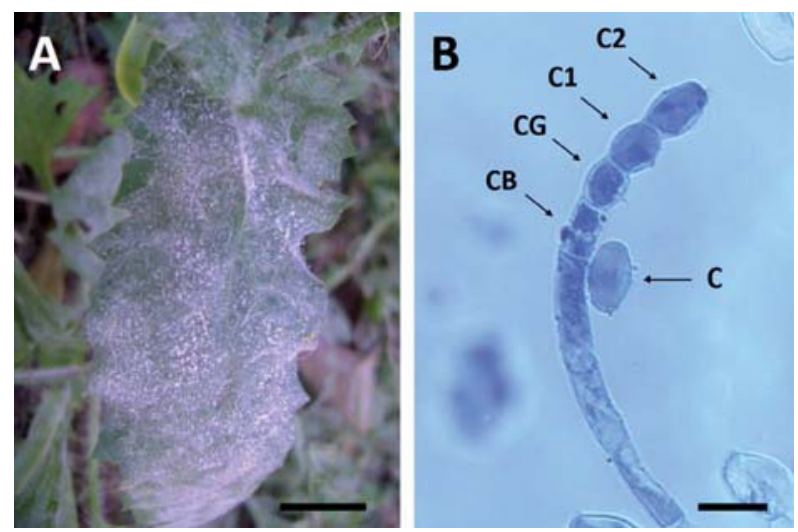

Figura 1. A-Folha de Emilia sonchifolia exibindo sintomas de oídio, caracterizado por uma massa pulverulenta branca-acinzentada na face adaxial; B. Conidióforo ereto de Fibroidium emiliae-sonchifoliae formado por uma célula basal (CB), uma célula generativa (CG), um conídio em primeiro estádio $(\mathrm{C} 1)$, um conídio em segundo estádio (C2) e um artroconídio maduro (C). (Barras correspondem a 1,8 cm e 26,0 $\mu \mathrm{m}$, respectivamente). em regiões diferentes, como exemplo pode-se citar isolados de Lasiodiplodia theobromae que possuem variações morfológicas e culturais em diferentes regiões (Lima et al., 2013). Em relação as células CG, C1 e C2 não foram encontrados trabalhos que contemplem a mensuração dessas estruturas, porém Whipps et al. (1998) relata a presença destas células em oídio na cultura do tomate.

Diferentemente, Zhao et al. (2010) encontrou Oidium cassiae-siameae em folhas de Cassia corymbosa, com artroconídios maduros medindo 31,5-62,3 x 13,4$22 \mu \mathrm{m}$, Estas medidas são diferentes das encontradas no presente estudo, principalmente ao se observar o comprimento máximo do artroconídio maduro, refutando a possibilidade de se tratar desta espécie. De forma análoga, Whipps (1998) relatou para folhas de Solanum lycopersicum a espécie Oidium lycopersicum, com valores de $\mathrm{CB}$ de $27,5-65,0 \times 5,0-7,5 \mu \mathrm{m}$, os quais são muito inferiores às medições obtidas da espécie de fungo encontrada nas plantas de falsa serralha do Setor de Horticultura da UEG. Quanto a Oidium caesalpiniacearum e Oidium asteris-punicei, relatadas por Rosa et al. (2008) e BARGUIL et al. (2007), estas espécies não podem ser consideradas, visto que as dimensões das CB do conidióforo não são conhecidas. Da mesma forma pode-se refutar a espécie Oidium hortensiae, pois as dimensões de suas CB $(32,0-50,0$ x 14,0 - 22,0 $\mu \mathrm{m}$ ) são muito diferentes de F. emiliaesonchifoliae (Park et al., 2012).

Em relação aos sintomas, Barguil et al. (2007) observou para a espécie Zinnia elegans, pertencente à família Asteraceae assim como Emilia sonchifolia, características pertencentes a oídio, tais como crescimento de micélio hialino e superficial, pulverulento, branco, cobrindo a face adaxial da folha, possuindo conidióforos eretos, cilíndricos, contendo de 2 a 4 células e conídios de formato elipsoides a ovais, correspondendo com as características encontradas no presente trabalho (Figura 1).

As temperaturas na cidade de Ipameri variaram de 12,0 a $32,0^{\circ} \mathrm{C}$ no mês de julho em 2013 . Esta condição, associada com a estiagem durante o período, favorece o desenvolvimento do oídio, o qual tem suas condições ótimas em temperaturas de 25 a $28^{\circ} \mathrm{C}$ (Liyanage et al., 2016). A estiagem prolongada possibilita a contaminação por parte do patógeno que possui esporos assexuais com capacidade de germinar na ausência de água (Severoglu \& Ozyigit, 2012). 
Tabela 1 - Características morfológicas de diferentes espécies de Oidium, ocorrentes em diferentes hospedeiros, incluindo Fibroidium emiliae-sonchifoliae, encontrado em plantas de falsa serralha no Setor de Horticultura da UEG. Ipameri, Goiás, Brasil, 2013

\begin{tabular}{|c|c|c|c|c|c|}
\hline \multirow[t]{2}{*}{ Espécie de fungo } & \multirow[t]{2}{*}{ Hospedeiro / órgão da planta } & \multicolumn{2}{|c|}{$\begin{array}{l}\text { Tamanho do artroconídio } \\
\text { maduro }(\mu \mathrm{m})\end{array}$} & \multicolumn{2}{|c|}{$\begin{array}{l}\text { Tamanho da célula basal } \\
\text { do conidióforo }(\mu \mathrm{m})\end{array}$} \\
\hline & & Comp. & Largura & Comp. & Largura \\
\hline Oidium cassiae-siameae $^{(1)}$ & Cassia corymbosa / folha & $31,5-62,3$ & $13,4-22,0$ & $39,7-53,0$ & $8,0-11,2$ \\
\hline Oidium lycopersicum ${ }^{(2)}$ & Solanum lycopersicum / folha & $22,5-37,5$ & $12,5-15,0$ & $27,5-65,0$ & $5,0-7,5$ \\
\hline Oidium caesalpiniacearum ${ }^{(3)}$ & Bauhinia forficata / folha & $26,8-43,5$ & $11,1-20,5$ & $*$ & $*$ \\
\hline Oidium asteris-punicei $^{(4)}$ & Zinnia elegans / folha & $25,0-32,5$ & $12,5-18,7$ & $*$ & $*$ \\
\hline Oidium hortensiae ${ }^{(5)}$ & Hydrangea macrophylla / folha & $*$ & $*$ & $32,0-50,0$ & $14,0-22,0$ \\
\hline Fibroidium. emilia-sonchifoliae ${ }^{(6)}$ & Emilia sonchifolia / folha & $32,0-40,0$ & $12,0-23,0$ & $48,0-72,0$ & $12,0-13,0$ \\
\hline Fibroidium emilia-sonchifoliae $^{(7)}$ & Emilia sonchifolia / folha & $23,1-31,9$ & $11,3-14,5$ & $45,3-91,4$ & $8,3-12,6$ \\
\hline
\end{tabular}

${ }^{(1)}$ Zhao et al. (2010); (2) Whipps et al. (1998); (3)Rosa et al. (2008); ${ }^{(4)}$ Barguil et al. (2007); ${ }^{(5)}$ Park et al. (2012); (6)Braun \& Cook (2012);

${ }^{(7)}$ Espécie encontrada em plantas de falsa serralha no Setor de Horticultura da UEG; *Não relatado pelos autores.

\section{CONCLUSÃO}

Os dados obtidos foram suficientes para cofirmar o agente cuasal do oídio em sua fase anamórfica, utilizando plantas de E. sonchifolia como hospedeiro alternativo da doença. Este é o primeiro relato da ocorrência de Fibroidium emiliae-sonchifoliae em Emilia sonchifolia no Estado de Goiás.

\section{AGRADECIMENTOS}

Os autores agradecem ao Programa de Bolsa de Incentivo à Pesquisa e Produção Científica (PROBIP) da Universidade Estadual de Goiás (UEG) por uma bolsa de produtividade em pesquisa.

\section{LITERATURA CITADA}

BARGUIL, B.M.; VIANA, F.M.P.; SARAIVA, H.A.O. Ocorrência de oídio em Zinnia elegans no Estado do Ceará. Summa

Phytophatologica, Botucatu, v.33, n.4, p.421, 2007.

BEDENDO, I.P. Oídios. In: AMORIM, L.; REZENDE, J.A.M.; BERGAMIM FILHO, A (Org.). Manual de Fitopatologia: Princípios e Conceitos. 4.ed. v.1. São Paulo: Agronômica Ceres, 2011, p.473-477.

BRAUN, U.; COOK, R.T.A. Taxonomic of the erysiphales (Powdery Mildews). CBS

Biodiversity Series, v.11, p.1-707, 2012.
COUTO, V.M.; VILELA, F.C.; DIAS, D.F. et al. Antinociceptive effect of extract of Emilia sonchifolia in mice. Journal of

Ethnopharmacology, Lausanne, v.134, p.348353, 2011.

FERREIRA, E.A.; PROCÓPIO, S.O.; SILVA, E.A.M. et al. Estudos anatômicos de folhas de espécies de plantas daninhas. II - Bidens pilosa, Emilia sonchifolia, Ageratum conyzoides e Sonchus asper. Planta daninha, Viçosa, v.20, n.3, 2002.

GONZALES, G.C.; CATANEO, A.C.; FIORI, M.S. et al. Pigmentos fotossintéticos em clones de seringueira sob ataque de oídio. Ciência Florestal, Santa Maria, v.23, n.3, p.499-506, 2013.

LIMA, C.S.; SOUZA, P.E.; BOTELHO, A.O. Fungos da família Pucciniaceae causadores de ferrugem em plantas medicinais. Fitopatologia Brasileira, Brasília, v.29, n.5, p.499-503, 2004.

LIMA, J.S.; MOREIRA, R.C.; CARDOSO, J.E. et al. Caracterização cultural, morfológica e patogênica de Lasiodiplodia theobromae associado a frutíferas tropicais. Summa Phytopathologica, Botucatu, v.39, n.2, p.8188, 2013.

LIYANAGE, K.K.; KHAN, S.; MORTIMER, P.E. et al. Powdery mildew disease of rubber tree. Forest Pathology, Aberdeen, v.46, p.90-103, 2016. 
MILÉO, L.J.; SILVA, J.F.; BENTES, J.L.S. et al. Plantas daninhas hospedeiras alternativas de Colletotrichum guaranicola em cultivos de guaraná no Estado do Amazonas. Planta Daninha, Viçosa, v.25, n.4, p.771-782, 2007.

PARK, M.J.; CHO, S.E.; PARK, J.H. et al. First Report of Powdery Mildew Caused by Oidium hortensiae on Mophead Hydrangea in Korea. Plant Disease, Saint Paul, v.96, n.7, p.1072, 2012.

RABELO, H.O.; SANTOS, L.S.; DINIZ, G.M.M. et al. Cucurbits powdery mildew race identify and reaction of melon genotypes. Pesquisa

Agropecuária Tropical, Goiânia, v.47, n.4, p.440-447, 2017.

ROSA, D.D.; BASSETO, M.A.; OHTO, C.T. et al. Ocorrência de Oídio (Oidium caesalpiniacearum Hosag \& W. Braum) em Pata de Vaca (Bauhinia forficata link.) no Brasil. Summa

Phytopathologica, Botucatu, v.34, n.2, p.196, 2008.

SEVEROGLU, Z.; OZYIGIT, I. I. Powdery mildew disease in some natural and exotic plants of Istanbul, Turkey. Pakistan Journal of
Botanic, v.44, p.387-393, 2012.

TUMURA, K.G.; PIZETTA, M.; SILVA, L.L. et al. Avaliação de clones de seringueira quanto à resistência ao oídio. Summa

Phytopathologica, Botucatu, v.39, n.4, p.252257, 2013.

VALARINI, P.J.; SPADOTTO, C.A. Identificação de nichos de sobrevivência de fitopatógenos em áreas irrigadas em Guairá, SP. Pesquisa

Agropecuária Brasileira, Brasília, v.30, n.10, p.1239-1243, 1995.

WHIPPS, J.M.; BUDGE, S. P.; FENLON, J. S. Characteristics and host range of tomato powdery mildew. Plant Pathology, Oxford, v.47, p.3648, 1998.

YAMASHITA, O.M.; GUIMARÃES, S.C.; SILVA, J.L. et al. Fatores ambientais sobre a germinação de Emilia Sonchifolia. Planta Daninha, Viçosa, v.27, n.4, p.673-681, 2009.

ZHAO, G.; LI, D.; XI, G. First report of powdery mildew caused by Oidium cassiae-siameae on Cassia corymbosa. Mycosystema, v.29, n.6, p.869-873, 2010.

Recebido para publicação em 8/4/2018 e aprovado em 4/9/2018. 